\title{
O Plano Nacional de Educação (Lei
} 10.172), de 9 de janeiro de $2001^{*}$

\section{The Educational National Plan (Law 10.172), January 9,2001}

\author{
Jorge Fernando Hermida**
}

\begin{abstract}
RESUMO
Este estudo procura compreender as motivações que alavancam os jogos de interesse e a luta pela hegemonia nacional nas atuais reformas em curso no Brasil - dentre elas a reforma educativa - inspiradas nas transformações que vêm ocorrendo em nível mundial e que têm profundas implicações para a educação. Dentre as principais políticas públicas, temos o "Plano Nacional de Educação (PNE) - Proposta do Poder Executivo para o Congresso Nacional”, que foi aprovado em janeiro de 2001. Até sua aprovação final, a proposta oficial foi objeto de debate no Parlamento com o projeto intitulado "Plano Nacional de Educação - Proposta da sociedade brasileira”. Este último foi elaborado junto aos sindicatos da educação e defendido por senadores e deputados da oposição ao governo daquele período (PSDB). A proposta deste artigo é realizar uma análise política das duas propostas para, através de um estudo exploratório, poder localizar, na legislação vigente, as origens das propostas do plano, seus pressupostos axiológicos básicos e os sujeitos políticos que geraram as mesmas.

Palavras-chave: políticas públicas; reforma educacional; processos legislativos.
\end{abstract}

\section{ABSTRACT}

* Para Gabriel Hermida (Gaby), filho querido.

** Doutor em Educação (Unicamp). Professor da Universidade Federal da Paraíba (UFPB). E-mail: jorgeferhermida@hotmail.com

${ }^{1}$ Dentre os especialistas consultados que se dedicaram a estudar as políticas públicas para 
HERMIDA, J. F. O Plano Nacional de Educação...

This study searches to understand the motivations, interests play and the fight for National hegemony of the actual reforms in Brazil - such as Educational Reform - inspired by the transformations occurring world wide with deep implications for Education. One of this Public polices is the Educational National Plan (PNE), proposed by the Executive Power to the National Congress, approved in January of 2001. Until its final approval, the official proposal was debated in the parliament with the PNE (a alternative proposal of the Brazilian society), elaborated together with educational syndicates, with support of senators and opposition congressman.This study pretends to realize political analyses of the two proposals, through an exploratory study, to find the origins of the proposals, its basic axiological premises and the political subjects behind its implementation.

Key-words: public polices; educational reform; legislators process.

\section{Introdução}

Este artigo tem como finalidade analisar uma das políticas mais importantes da atual reforma educacional, aprovada no Congresso Nacional: o Plano Nacional de Educação (PNE), de 09 de janeiro de 2001. Ele foi aprovado na época em que o governo de Fernando Henrique Cardoso consolidava um conjunto de reformas, com a finalidade de elaborar um modelo educativo de acordo com as políticas gerais - denominadas por muitos especialistas e associações estudantis e sindicais como sendo de cunho neoliberal ${ }^{1}$ e neoconservador ${ }^{2}$ - desenvolvidas até então nos âmbitos financeiro, político, econômico, industrial e social. As reformas, propostas sob o rótulo de “modernização nacional”, responderam à

a educação e que denominam o atual processo de reformas como neoliberal e neoconservador estão: GENTILI, P.; APPLE, M. W. et al. (Pedagogia da exclusão: crítica ao neoliberalismo em educação. Petrópolis: Vozes, 1995.); KATZ, C. e CAGGIOLA, O (Neoliberalismo ou crise do capital? São Paulo: Xamã, 1996. $2^{\text {a }}$. ed.); SILVA, T. T. e GENTILI, P. (Neoliberalismo, qualidade total e educação: visões críticas. Petrópolis: Vozes, 1998); e SADER, E., GENTILI, P. e BARAN, A. (Pós-neoliberalismo: as políticas sociais e o estado democrático. São Paulo: Paz e Terra, 1996), dentre outros.

${ }^{2}$ As principais associações estudantis e sindicais que utilizaram nos seus documentos essa denominação para se referirem ao processo de reformas empreendido pelo governo de Fernando 
necessidade do governo de adequar o Estado às significativas mudanças que ocorriam no mundo capitalista. Independentemente do âmbito onde se produziam as reformas, as expressões que orientaram os processos foram sempre as mesmas: "modernização da sociedade”, "inovação tecnológica”, "erradicação da pobreza", "adequar a educação e o mundo do trabalho às novas tecnologias" e a "consolidação da ordem social" como horizonte. Para se adequar a esse contexto político, o governo de Fernando Henrique Cardoso valeu-se dos mais diversos instrumentos: desde a aprovação de projetos de lei, propostas de emendas constitucionais, medidas provisórias, decretos e portarias. Foi através desses instrumentos que o Ministério da Educação (MEC) começou a concretizar suas iniciativas reformistas.

Dentre as principais políticas públicas, destaca-se a Lei n. 10.172, que aprova o Plano Nacional de Educação, em 09 de janeiro de 2001. A elaboração e apresentação de um plano para a educação responderam a exigências previstas na Constituição Federal de 1988, na Lei n. 9.131, de 24 de novembro de 1995 e na Lei de Diretrizes e Bases da Educação Nacional (LDBEN) - Lei n. 9.394, de 20 de dezembro de 1996. Até chegar a sua aprovação final, a proposta oficial foi discutida no Parlamento com o projeto de "Plano Nacional de Educação - Proposta da sociedade brasileira”, elaborado pela sociedade civil, que se organizou junto aos sindicatos e trabalhadores da educação e que foi defendida por senadores e deputados de oposição ao governo daquele período. Assim sendo, este estudo pretende realizar uma análise política que, através de um estudo exploratório, procura localizar as origens das propostas, detectar os sujeitos históricos que inspiraram as mesmas e priorizar a análise de alguns pressupostos axiológicos que permearam a ambas propostas.

\section{O Plano Nacional de Educação na legislação vigente}

\footnotetext{
Henrique Cardoso foram: a Associação Nacional de Pós-graduação e Pesquisa em Educação (Anped), a Associação Nacional dos Docentes das Instituições de Ensino Superior (Andes), a Associação de Pós-graduandos da Unicamp (APG/Unicamp), a Confederação Geral dos Trabalhadores (CGT), a Central Única dos Trabalhadores, a Federação da Associação dos Servidores das Universidades Brasileiras (Fasubra), a União Brasileira de Estudantes Secundaristas (Ubes) e a União Nacional dos Estudantes (UNE).

${ }^{3}$ Ao tratar da "proposta oficial” de Plano Nacional de Educação, Cury (1998) também detectou a existência de duas posições contraditórias, que no seu artigo "Plano Nacional de Educação: duas
} 
HERMIDA, J. F. O Plano Nacional de Educação...

A Constituição Federal de 1988 (CF/88), conhecida também como "Constituição Cidadã" constitui um dos instrumentos legais que tratam deste assunto. O artigo 214 da CF/88 (BRASIL, 1999, p. 119) determina que

\begin{abstract}
A lei estabelecerá o plano nacional de educação, de duração plurianual, visando à articulação e ao desenvolvimento do ensino em seus diversos níveis e à integração das ações do Poder Público que conduzam à:

I. erradicação do analfabetismo;

II. universalização do atendimento escolar;

III. melhoria da qualidade de ensino;

IV. formação para o trabalho;

V. promoção humanística, científica e tecnológica do País. (BRASIL, 1999, p. 119)
\end{abstract}

Uma outra lei que trata sobre o plano é a Lei n. 9.131/96. Nela se determina que, no desempenho de suas funções, o Ministério da Educação contará com a colaboração do Conselho Nacional de Educação (CNE) na formulação e avaliação da política nacional de educação, para zelar pela qualidade do ensino e velar pelo cumprimento das leis que o regem.

Assim sendo, no artigo $7^{\circ}$ dessa lei, é possível encontrar as atribuições do Conselho (CNE): "normativas”, “deliberativas” e "de assessoramento” ao Ministério da Educação, tendo como finalidade assegurar “... a participação da sociedade no aperfeiçoamento da educação nacional.” $\mathrm{O} \S 1^{\circ}$ desse artigo considera que "Ao Conselho Nacional de Educação, além de outras atribuições que lhe forem conferidas por lei, compete: subsidiar a elaboração e acompanhar a execução do Plano Nacional de Educação.”

Entretanto, o artigo $9^{\circ}$ da LDBEN dispõe que "A União incumbir-se-á de: I. elaborar o plano nacional de educação, em colaboração com os Estados, o Distrito Federal e os Municípios.” A LDBEN ainda determina:

Art. 87 - É instituída a Década da Educação, a iniciar-se um ano a partir da publicação desta lei. § $1^{\circ}$ A União, no prazo de um ano a partir da publicação desta lei, encaminhará, ao Congresso Nacional, o Plano Nacional de Educação, com diretrizes e metas para os dez anos seguintes, em sintonia com a Declaração Mundial sobre Educação para Todos. 
Junto como a Emenda Constitucional n. 14, esses dispositivos constitucionais e legais definem a natureza do Plano Nacional de Educação: a responsabilidade de sua elaboração caberá à União, em colaboração com os Estados, Distrito Federal e Municípios; é fixado o prazo de um ano, a contar da aprovação da Lei n. 9.394/96 (LDBEN) para a remessa de propostas para o Congresso Nacional; estabelecem sua vigência (dez anos); e, uma vez aprovado pelo Congresso Nacional, o plano adquirirá força de Lei.

O Plano Nacional de Educação é a principal lei que decorre da nova LDBEN. Esse fato foi reconhecido tanto pelas autoridades educativas nacionais como também pelas numerosas associações de professores e estudantes e sindicatos vinculados ao campo da educação, historicamente localizados na oposição política ao processo de reformas, em especial depois que Fernando Henrique Cardoso chegou ao governo nas eleições nacionais para a presidência da República, em 1994 e 1998. O marco jurídico supracitado permitiu que se iniciassem os primeiros esforços para a elaboração de propostas. Estas foram desenvolvidas por sujeitos históricos diferentes, que elaboraram e colocaram em confronto, no Congresso Nacional, projetos de planos antagônicos e antitéticos.

\section{As origens das propostas e seus mentores}

As primeiras iniciativas oficiais ocorreram em meados de 1997, quando, através de documento específico intitulado "Plano Nacional de Educação - proposta inicial dos procedimentos a serem seguidos”, o Ministério da Educação divulgou sua proposta. Nela era delineada a principal estratégia de elaboração: o futuro plano deveria privilegiar processos de consultas e debates junto à comunidade educacional e seus especialistas. Para atingir essa finalidade foram estabelecidos prazos, com a expectativa de poder retomar as dinâmicas e experiências ocorridas quando da época da elaboração do Plano Decenal de Educação nos anos de 1993 e 1994 (BRASIL/MEC; 1997).

Na época da elaboração do Plano Decenal de Educação Para Todos (durante o governo Itamar Franco), já era possível identificar iniciativas no sentido de redefinir prioridades educacionais a partir dos objetivos e diretrizes estabelecidas e apontadas pelos principais organismos internacionais: a Organização das Nações Unidas para a Educação, a Ciência e a Cultura (Unesco), 
o Fundo das Nações Unidas para a Infância (Unicef), o Banco Mundial e o Fundo Monetário Internacional (FMI). As iniciativas educacionais apresentavam uma natureza neoliberal - que se localiza nas fontes e nas finalidades que inspiraram a proposta - constituídas de teorias externas que procuravam contribuir para a construção de um projeto histórico defensor de interesses das agências financiadoras articuladas ao capital internacional. A problemática das fontes externas e de intelectuais estrangeiros orientando processos de elaboração de documentos para a educação não era nova, pois ela se manifestava também em outros países da América Latina. Basicamente eram inspirados em expressões encontradas, nas últimas décadas, na "Aliança para o Progresso", nas incursões da United States Development Agency (USAID), nos projetos da UNESCO/CEPAL/PNUD e nas diretrizes do Banco Mundial, cujas palavras de ordem eram qualidade, produtividade e equidade. (cf. sAviAnI, 1996)

As teses centrais do Plano Decenal de Educação para Todos - estreitamente ligadas às teses aprovadas na Conferência de Nova Déli - eram consensuais e expressavam o anseio e a necessidade de assegurar a todas as crianças, jovens e adultos os conhecimentos básicos indispensáveis para o desenvolvimento de uma "vida produtiva", considerada no documento como "pedra angular do regime democrático.” Essas eram as primeiras providências adotadas pelos grupos dominantes (o estabelecimento de objetivos e prioridades seguindo diretrizes externas) que, com o passar do tempo, se tornaram sistemáticas.

Do ponto de vista do seu conteúdo, na Introdução de seu texto, o Plano Decenal afirmava não querer confundir-se com a discussão do Plano Nacional de Educação que regularia todos os níveis e modalidades de ensino; ele abrangia somente o campo da educação básica, que era considerada prioridade nacional.

Apesar de seu teor neoliberal, o Plano Decenal previu processos de participação que se configuraram como um pacto social. De fato, o plano foi elaborado por um Grupo Executivo, um Comitê Consultivo e por representantes de organismos internacionais ligados à educação. Entretanto, cabe ressaltar que seu processo de elaboração foi permeado e influenciado pelas particularidades, que refletiam os processos que vinham ocorrendo na sociedade brasileira.

Dentre as principais particularidades, tomando questões em nível social, está o conflito que ele gerou nas entidades integrantes do Fórum Nacional em Defesa da Escola Pública na LDBEN, considerando que as participações nas discussões dos Planos Decenais desviaram a atenção da sociedade das discussões travadas sobre as diretrizes e bases no Congresso Nacional e, conseqüentemente, esvaziaram o Fórum na LDBEN. Isso ocorreu em um momento por demais especial: a dois meses da sucessão presidencial, quando 
as pesquisas de opinião davam como ganhador por avassaladora maioria o candidato conservador (Fernando Henrique Cardoso), que tinha uma proposta de governo neoliberal.

Organizada de forma tópica, a proposta inicial dos procedimentos a serem seguidos reproduzia as disposições legais encontradas na $C F / 88$, na LDBEN - Lei n. 9.394/96 e na Lei n. 9.131/95; também era apresentada a estratégia a ser seguida para a elaboração do documento que considerava como interlocutores privilegiados o Conselho Nacional de Educação (CNE), o Conselho Nacional de Secretários de Educação (CONSED) e a União Nacional dos Dirigentes Municipais de Educação (UNDIME). Na proposta inicial, o plano era organizado da seguinte forma: "I - Educação Infantil e Ensino Fundamental; II - Ensino Médio; III - Ensino Superior; IV - Educação Tecnológica e Formação Profissional; V - Educação Especial; VI - Educação Indígena; VII - Formação de Professores; VIII - Educação de Jovens e Adultos e erradicação do analfabetismo; e IX - Educação à Distancia” (cf. Brasil/MEC; 1997a).

Estabeleceu-se que a elaboração final deveria ser realizada de forma coordenada entre o Ministério da Educação e o Instituto Nacional de Estudos e Investigações Educacionais (INEP), a partir das contribuições oriundas do Conselho Nacional de Educação, da Secretaria de Educação Fundamental (SEF), da Secretaria de Ensino Superior (SESu) e da Secretaria de Educação Especial (SEE). O tópico 4 da proposta inicial apresentava o cronograma junho-dezembro de 1997, no qual se estabeleciam os passos que deviam ser seguidos pelos futuros autores. No seu estágio final, a proposta seria discutida pelos secretários do Ministério da Educação e do produto das discussões resultaria a proposta do Executivo a ser encaminhada para o Congresso entre a segunda quinzena de novembro e a primeira de dezembro. (BRASIL/MEC, 1997a; SAVIANI, 1998)

Atendendo ao disposto na proposta inicial dos procedimentos a serem seguidos, o Executivo elaborou um novo documento que recebeu o nome de "Proposta para o Documento: Roteiro e Meta para Orientar o Debate sobre o PNE.” A proposta apresentava metas que eram definidas como "... consoantes com as atuais políticas educacionais.” Elas procuravam consolidar os compromissos já assumidos pelo governo, tendo como escopo a melhoria da eficiência e da qualidade do ensino em todos os seus níveis. Posteriormente o roteiro se desdobrava em metas quantitativas e qualitativas para as seguintes áreas de ensino: Ensino Fundamental, Educação Infantil-Creches, Educação Infantil-Pré-escola, Educação Especial, Ensino Médio, Educação Profissional, Educação de Jovens e Adultos, Ensino Superior, Educação a Distância, Educação Indígena, para a Formação de Professores e a Valorização do Magistério e Financiamento e Gestão. Finalmente, o roteiro declarava que o Brasil 
HERMIDA, J. F. O Plano Nacional de Educação...

requeria novos desafios educativos, que colocassem o país em um novo patamar de cidadania, compatível com os dos países desenvolvidos (BRASIL/MEC, 1997b, p. 02).

Nesta primeira proposta do Plano Nacional de Educação, já se vislumbram os princípios e a filosofia a ser encontrada mais tarde na proposta final do Poder Executivo. Nesta, encontra-se assegurado que a responsabilidade pela execução havia sido delegada para os Estados e Municípios; além disso, no texto também se observa o recuo da União em matéria de recursos e orçamento, pois consolida a racionalização e otimização dos recursos já existentes, acompanhado de um discreto aumento que, no prazo de dez anos, chegaria a atingir 6,5\% do Produto Interno Bruto (PIB) - incluídos recursos provenientes do setor privado. Ao analisar as metas, percebe-se que há um repasse de responsabilidades da União para os Estados e Municípios. Em seu conjunto, o plano prioriza o Ensino Fundamental, através de metas concretas, sobretudo quando é ofertado para populações de baixa renda, em detrimento de outras áreas de ensino que ficam completamente desamparadas (a educação de adultos e o combate ao analfabetismo). A formação de professores considerada prioritária, fica inviável ao não se explicitar de onde virão os recursos para tal fim.

A falta de definição orçamentária faz com que muitos compromissos, apesar de serem considerados prioritários, sejam questionados e colocados em dúvida. Em síntese, as metas e objetivos do plano fazem com que a organização educacional se aproxime dos princípios já explicitados na LDBEN de 1996. Pode-se afirmar que nela coexistiam duas posições contraditórias: uma, conservadora, já que as prioridades anunciadas estão garantidas em outras leis e decretos - que não aportava nada ao já existente no âmbito nacional; e uma segunda posição, que é chamada, neste estudo, de idealista, pois o mero enunciado dos problemas e carências educativas não basta para solucionar os mesmos, tendo em vista as carências orçamentárias detectadas. ${ }^{3}$

Entretanto, a sociedade civil organizada junto aos sindicatos dos trabalhadores da educação não se manteve indiferente. Através da organização de eventos, foi elaborando sua própria proposta. O I Congresso Nacional de Educação (Coned), organizado no final do ano de 1996, na cidade de Belo Horizonte/MG, assumiu o compromisso de retomar as lutas desenvolvidas até então pelo Fórum Nacional em Defesa da Escola Pública (que teve papel relevante na defesa de sua proposta de LDBEN) e se notabilizou pela tarefa

formulações”, as definiu como sendo “conservadora” e “utópica.”

${ }^{4}$ Lembre-se que, no primeiro turno das Eleições Nacionais de 2002, de um total de 94.780.248 votos apurados (100\%), o candidato que oferecia mais "perspectivas de mudanças" - Luis Inácio Lula da Silva (PT) obteve 39.443.765 votos (46,4\% dos votos válidos); a candidatura oficial 
de elaborar, junto ao coletivo de trabalhadores da educação, uma proposta de plano inovador capaz de dar novos rumos à educação nacional. A partir da lógica defendida neste evento, amplos segmentos da sociedade civil se organizaram para intervir também diretamente na elaboração de uma proposta de plano para a educação nacional. Promovendo extensos debates das pesquisas e experiências educacionais, a proposta foi construída em oposição àquela que vinha sendo viabilizada pelo governo e procurou apresentar-se como alternativa ao modelo educativo vigente, para finalmente constituir-se num projeto político-pedagógico para a educação brasileira, pautado na ética e na participação democrática.

Pouco antes da realização do II CONED, no ano de 1997, setores organizados junto à Associação Nacional de Pós-Graduação e Pesquisa em Educação (Anped) elaboraram um parecer sobre a proposta do governo, produzido durante as reuniões promovidas pela entidade cuja finalidade era a discussão da "Proposta para o Documento: Roteiro e Meta para Orientar o Debate sobre o PNE.” No parecer, o grupo de trabalho constituído para tal fim apresentava críticas diversas, que questionavam tanto o método adotado para a elaboração da proposta quanto os conteúdos das metas; também eram alvo das críticas a política educacional do governo e o descaso com que foram tratadas muitas das contribuições encaminhadas por diferentes setores às autoridades nacionais. Dentre as principais críticas, estavam as que exigiam considerável ampliação dos investimentos públicos para a educação, assim como as que denunciavam as escassas ambições quanto ao conteúdo do projeto, a utilização de dados desatualizados, de 1989, e a não incorporação das contribuições encaminhadas por segmentos da sociedade civil, em especial, as que faziam referencia à indefinição sobre a origem dos recursos, que davam à proposta oficial um caráter retórico (cf. ANPED, 1997). A mesma perspectiva crítica que caracterizou o parecer elaborado pela Associação Nacional de Pós-Graduação e Pesquisa em Educação foi retomada quando da realização do II Coned (Belo Horizonte, novembro de 1997), mas de uma forma mais radical. Concomitante a isto, a proposta do Poder Executivo seguiu inexoravelmente os rumos traçados no roteiro de metas para orientar o debate sobre o plano.

Desta forma já estava delineada a alternativa para a elaboração da proposta do Plano Nacional de Educação pelo coletivo de trabalhadores da educação. Diante dessa realidade, a sociedade civil também se organizou para intervir, promovendo amplos debates através da análise e discussões coletivas de experiências educacionais, elaborando, na forma de propostas, caminhos alternativos àqueles praticamente impostos pelo governo nacional. Dentre os setores organizados no campo específico da educação, destacam-se os de professores e estudantes reunidos em torno do I e II Congresso Nacional 
de Educação (Coned) e da União Nacional dos Estudantes (UNE), em torno do Sindicato Nacional de Associações Docentes (Conad) e do Sindicato Nacional de Docentes das Instituições de Ensino Superior (Andes-SN) e, para reverter o quadro de sucateamento do setor de Ciência e Tecnologia, os setores organizados e mobilizados na Frente de Defesa do Sistema Nacional de Ciência e Tecnologia (criado na 49 $9^{\mathrm{a}}$ Reunião Anual da SBPC, em julho de 1997) e na Frente Parlamentar em Defesa do Sistema Nacional de Ciência e Tecnologia. Os professores reunidos nesses eventos e associações sindicais e científicas discutiram, debateram e elaboraram propostas com a finalidade de constituir um modelo político-pedagógico alternativo “... pautado na ética e na participação democrática” (Plano Nacional de Educação - Proposta do II CONED, 1997, p. 13).

Apoiando-se no artigo 214 da Constituição Federal de 1988 e no artigo 87 da nova LDBEN (Lei n. 9.394/96), a Comissão Organizadora do II CONED elaborou um documento que sistematiza os resultados das discussões e dos estudos realizados em diversos eventos organizados previamente em todo o país, como o I CONED, os CONADS, Seminários Temáticos Nacionais e Locais. Por isso, considera-se que o II CONED sintetiza o esforço coletivo de construção do plano. Ele é produto das discussões realizadas em 1996 e 1997 sob a coordenação e apoio das entidades do Fórum Nacional em Defesa da Escola Pública. Nele, as concepções adotadas de ser humano, educação, escola, democracia, sociedade, autonomia, gestão e currículo, dentre outras, diferenciam-se das concepções governamentais, expressas nas políticas públicas educacionais aprovadas ultimamente na forma de leis, decretos e medidas provisórias. Pode-se encontrar na proposta que

A tarefa inédita a que se propuseram os setores organizados da sociedade civil (através de suas entidades científicas, acadêmicas, sindicais, estudantis de âmbito nacional e local) e de parcela da sociedade política representada, sobretudo, por algumas administrações municipais e alguns parlamentares, se de um lado, resgata o método democrático de construção do projeto de Lei de Diretrizes e Bases da Educação Nacional - LDB - da Câmara Federal, de outro tenta, na medida do possível, recuperar seu conteúdo, em especial aquele que expressa os anseios da maioria da população, recolocando direitos que constam da Constituição Federal de 1988 que, se cumpridos, amenizariam o descaso com que o governo Fernando Henrique Cardoso tem tratado a educação. (Plano Nacional de Educação - Proposta do II CONED, 1997, p. 13) 
Enquanto proposta político-pedagógica alternativa, o Plano Nacional de Educação, proposto no II CONED em 1997, se autodefine como um instrumento que foi elaborado em função da política educacional a ser implementada, da legislação que lhe dá suporte e das condições humanas, materiais e financeiras à disposição da sociedade. "Seu principal objetivo é atender às necessidades educacionais da maioria da população - ele é, por concepção, socialmente includente. Outrossim, tanto o método quanto o conteúdo desse plano refletem o caráter coletivo e democrático de sua própria implementação e avaliação" (Idem, p. 15). No plano, a educação é entendida como “... um instrumento de formação ampla, de luta pelos direitos da cidadania e da emancipação social” que deve contribuir com o aprimoramento do indivíduo e da sociedade para a construção coletiva de um novo projeto de inclusão e de qualidade social para o Brasil. O plano apresenta a educação como um instrumento fundamental, que deveria contribuir para o desenvolvimento econômico, social, cultural e político do país e também deveria garantir os direitos básicos da cidadania e da liberdade social. Nesta perspectiva, a educação é concebida como um patrimônio social. Como decorrência, e depois de meses de estudos, debates e planejamentos desenvolvidos junto a entidades representativas da sociedade, foram adotadas, dentre várias outras, as seguintes diretrizes para a educação:

Garantia de que, o Fórum Nacional em Defesa da Escola Pública, através do II CONED, enquanto instância da sociedade civil, seja reconhecido como interlocutor legítimo junto ao poder público, no encaminhamento do Primeiro Plano Nacional de Educação; (...) Construção e constituição do Fórum Nacional de Educação, majoritariamente integrado por representantes de vários segmentos sociais, através de entidades de âmbito nacional, além de representação de poderes constituídos; (...) Seja uma instância de luta e formação pela cidadania, preparando a sociedade na responsabilidade de construir coletivamente, um novo projeto social para a nação; (...) Acesso e permanência à educação pública gratuita, democrática, laica e de qualidade para todos os níveis; (...) Universalização da Educação Básica (Infantil, Fundamental e Média); (...) Regulamentação (normatização e fiscalização) do setor privado de ensino como concessão do poder público; (...) Garantia de autonomia universitária; (...) Indissociabilidade entre as atividades de ensino, pesquisa e extensão na universidade. (Plano Nacional de Educação - Proposta do II CONED, 1997, p. 17-18) 
HERMIDA, J. F. O Plano Nacional de Educação...

Os níveis de organização e mobilização atingidos na elaboração do plano em 1997, além de apresentarem avanços significativos com relação aos conteúdos propriamente ditos, constituíram-se como caminhos de resistência contrapostos aos projetos governamentais para a educação nacional. O plano discutido e aprovado no II CONED se apresenta como uma proposta políticopedagógica contrária ao projeto hegemônico da nova LDBEN sancionado pelo Senado em dezembro de 1996. O plano consiste, sobretudo num documento político, que a todo o momento procura pautar sua identidade em oposição à proposta do Poder Executivo. A proposta aponta a denúncia do não cumprimento, pelo governo, dos preceitos constitucionais educacionais. Por isso o Plano Nacional de Educação é coerente quando recusa a proposta de LDBEN aprovada no Congresso e procura buscar suas bases no projeto construído pela sociedade junto à Câmara dos Deputados, em 1989.

É assim que chega o ano de 1998. As forças congregadas em torno ao II coNED anteciparam-se ao governo federal e encaminharam ao Congresso o "Plano Nacional de Educação - proposta da sociedade brasileira”. Além disso, houve um movimento social que teve como objetivo transformar o referido plano em Projeto de Lei de Iniciativa Popular. Enquanto principal medida de política educacional decorrente da nova LDBEN, a importância do plano reside no fato de se apresentar como uma política de caráter global: nela se estabelece a futura organização da educação nacional, as metas e os objetivos a serem atingidos nos dez anos seguintes. Por isso esta se constituiu numa referência privilegiada para a análise do atual momento histórico da política educacional.

\section{Os projetos de Plano Nacional de Educação e seus processos legis- lativos}

O "Plano Nacional de Educação - proposta da sociedade brasileira" foi apresentado no Congresso Nacional pelo Deputado Federal Iván Valente (PT/SP), e por outros deputados de oposição ao governo de Fernando Henrique Cardoso. Por ocasião de sua apresentação na Câmara dos Deputados, inicia-se sua tramitação na Comissão de Educação da Câmara dos Deputados (CECD) com o número 4.155/98. Dias depois, deu entrada no Congresso o projeto de plano elaborado pelo Poder Executivo que, identificado como sendo o projeto $4.173 / 98$, começa a tramitar juntamente à primeira proposta. Assim que 
a Comissão de Educação da Câmara dos Deputados é instalada, nomeia-se o deputado Nelson Marchezán (PSDB/RS) como seu relator. Ao iniciar seus trabalhos, o deputado Marchezán não aceita o projeto da sociedade civil como referência para a elaboração de um substitutivo e sim a proposta de plano do Poder Executivo porque, na opinião dele, a proposta era mais 'realista' e também continha metas mais "concretas".

Diante disso, o Fórum Nacional em Defesa da Escola Pública começa a articular estratégias junto ao bloco de oposição política ao governo no Congresso Nacional, para garantir a participação da sociedade civil através da realização de audiências públicas. A primeira delas ocorreu em dezembro de 1998, e continuaram nos meses de abril a agosto de 1999. Apesar da atenção dedicada pelo relator, as dezesseis audiências realizadas não conseguiram garantir o tempo e o espaço necessários ao debate sobre um plano educacional. A última delas, realizada com o Ministro da Educação, Paulo Renato de Souza, caracterizou-se pela falta de quorum na Câmara dos Deputados. Após a finalização das audiências, o relator elaborou um relatório que incluiu a aprovação de projeto substitutivo que se transformou no projeto da Comissão de Educação da Câmara dos Deputados (CECD), em 8 de dezembro de 1999. O projeto da sociedade civil ficou definitivamente descartado.

Os deputados progressistas tentaram alterar o teor do texto através da realização de emendas. No total de 160 , não alcançaram as mudanças na lógica do plano proposto pelo Executivo. Diante dessa realidade adversa, o movimento docente redefiniu suas estratégias no III Congresso Nacional de Educação (CONED), realizado em Porto Alegre em dezembro de 1999. Na reunião plenária final do Congresso foi aprovada a Carta de Porto Alegre, que definia estratégias de luta para curto, médio e longo prazo, tendo em vista garantir a implantação de um projeto de plano alternativo. Entretanto, o projeto aprovado na Comissão de Educação da Câmara seguiu sua tramitação no Senado, como sendo o Projeto de Lei n. 42/2000 e na Comissão de Educação do Senado (CES) foi indicado José Jorge (PFL/PE), como relator.

Depois de realizadas várias audiências públicas, foi aprovado o Plano Nacional de Educação. Em 9 de janeiro recebe sanção presidencial, contendo nove vetos. De fato, na lógica do governo, os artigos vetados "feriam" a Lei de Responsabilidade Fiscal, além de não serem compatíveis com o Plano Plurianual vigente. Na tentativa de combate aos vetos, a sociedade civil se articula através da Campanha Nacional do Direito à Educação, que teve como articulador o senador José Dutra (PT/SP).

Em 20 de junho de 2001, ocorre a audiência pública na Comissão de Educação da Câmara dos Deputados para debater os vetos. De maneira sur- 
preendente, a Comissão se mostra favorável a sua derrubada. Nessa ocasião, a Campanha Nacional pelo Direito à Educação entrega ao Presidente da Comissão, o deputado Walfrido Mares Guia, um abaixo-assinado contendo mais de 18 mil assinaturas. Em 8 de agosto de 2001, ocorre uma audiência pública na Comissão de Educação da Câmara, na qual esteve presente o Ministro da Educação, Paulo Renato de Souza. Após tratar do tema, o Ministro manifesta a possibilidade de rever o veto junto ao Presidente da República. A sociedade civil uma vez mais se fez presente, através da apresentação ao Ministro da Educação de três moções solicitando a derrubada dos vetos. As moções haviam sido elaboradas pelo Congresso de Leitura do Brasil, pelo Movimento Interfóruns de Educação Infantil do Brasil e pelo Fórum em Defesa da Educação Infantil de Pernambuco.

O passo seguinte adotado pela sociedade civil foi a entrega, ao presidente do Congresso Nacional, senador Ramez Tebet, de uma carta contendo 50 assinaturas de entidades de todo o país, exigindo que se marcasse a sessão conjunta para a votação dos vetos.

O processo de discussão, tramitação e de aprovação do Plano Nacional de Educação no Congresso Nacional confirma a mudança nas estratégias de ação do Estado para a aprovação das políticas educacionais, a partir de 1995. Dentre as estratégias utilizadas, estiveram: a interferência do Poder Executivo no processo de elaboração das leis para a educação nacional, através da obstrução da tramitação dos projetos e da apresentação de projetos de leis substitutivos próprios (de forma simultânea aos processos de obstrução). Do ponto de vista histórico, esta estratégia - introduzida na dinâmica parlamentar quando Fernando Collor assumiu a presidência em 1991 - tornar-se-ia sistemática e dominante nos governos de Fernando Henrique Cardoso 1995-1998 e 1999-2002. Para exemplificar este fato é importante ressaltar que a interferência do Poder Executivo nos processos legislativos fez com que, em 1995, ocorresse um fato inédito na história da educação do país: a LDBEN começou a ser regulamentada mesmo antes de ser aprovada, em dezembro de 1996. A aprovação do conjunto de normas jurídicas conformadas pelas leis 9.131 e 9.192, de 1995, pela Emenda Constitucional n. 14, de setembro de 1996 e pelo Decreto n. 2.026, de outubro de 1996, ocorreu enquanto a LDBEN - que incluía no corpo do seu texto muitos assuntos regulamentados pelas normas jurídicas supracitadas, tramitava ainda no Congresso Nacional.

Com a implementação da reforma educacional através dessas estratégias, as ações do Poder Executivo começaram a predominar sobre as do Poder Legislativo. Diante desse quadro, a aprovação da legislação específica para a educação nacional passou a ser orientada por critérios político-partidários descaracterizando a forma participativa assumida pela sociedade política e 
civil no epílogo dos anos oitenta e no começo dos anos noventa. Do ponto de vista ideológico, as maneiras de obstruir e de apresentar um projeto substitutivo próprio podem ser entendidas como alinhamento das políticas educacionais em consonância com objetivos de natureza neoliberal elaborados pelos organismos internacionais, principalmente pelo Banco Mundial e pelo Fundo Monetário Internacional (FMI). Nesta nova perspectiva, os sistemas educacionais passaram a ser redefinidos no bojo das reformas estruturais encaminhadas principalmente pelo Banco Mundial que se torna, no dizer de Leher (1999), o Ministério Mundial da Educação dos países periféricos. No cerne da ideologia da globalização, as diretrizes do Banco Mundial consideravam apenas a dimensão estritamente instrumental da educação face à nova dinâmica do capital, numa perspectiva estritamente economista, “... contribuindo para a hipertrofia da crença no determinismo tecnológico, com significativas conseqüências desmobi-lizadoras” (LEHER, 1999, p. 20).

\section{Considerações finais}

Face aos acontecimentos aqui relatados, fica evidente que existiram dois projetos de Plano Nacional de Educação, de naturezas diferentes e antitéticas, que vislumbraram, na sua complexidade, o confronto de princípios e idéias no que diz respeito a concepções de homem, de educação e de sociedade. O confronto ocorrido no Congresso Nacional refletiu as discussões desencadeadas na sociedade civil em torno dos numerosos problemas que afligiam a sociedade brasileira. Um dos projetos, elaborado nos gabinetes do Ministério da Educação e do Instituto Nacional de Estudos e Investigações Educacionais (MEC/INEP), representava os interesses e privilégios de classe dominante, e o outro, apresentou-se como proposta alternativa aos projetos hegemônicos.

Os sujeitos históricos do projeto elaborado nos gabinetes do MEC/INEP foram o Poder Executivo e as esferas vinculadas ao poder dominante. Embora a lógica que permeou as propostas sempre fosse financeira, seus mentores foram incapazes de apresentar uma proposta orçamentária coerente. A ênfase educativa foi colocada no Ensino Fundamental, acima dos outros níveis de ensino. Por esta razão, a visão social que emana dos escritos oficiais é de uma sociedade fragmentada - pois em termos educativos muitos dos problemas que afligiam a educação brasileira sequer foram contemplados. 
HERMIDA, J. F. O Plano Nacional de Educação...

Nesta nova perspectiva, os sistemas educacionais passaram a ser redefinidos no bojo das reformas estruturais encaminhadas principalmente pelo Banco Mundial, que se torna, no dizer de Leher (1999), o Ministério Mundial da Educação dos países periféricos. No cerne da ideologia da globalização, as diretrizes do Banco Mundial consideravam apenas a dimensão estritamente instrumental da educação face à nova dinâmica do capital, numa perspectiva estritamente economista.

No texto oficial, a democracia se restringiu à sua forma representativa, restrita, pois quando muito os representantes da sociedade civil se remeteram a realizar contribuições que chegavam ou não a ser consideradas. A partir deste conceito de democracia, constitui atribuição dos representantes políticos escolhidos pelo povo - e não ao coletivo dos trabalhadores da educação organizados junto a seus sindicatos e organizações sociais e trabalhistas - aprovar ou modificar as diretrizes e metas educacionais no ambiente restrito do Congresso Nacional.

O outro projeto de plano, elaborado por entidades sindicais e estudantis, associações acadêmicas, universitárias e científicas, apresentou-se como representando alternativa aos projetos hegemônicos. O texto, que foi elaborado no II Congresso Nacional de Educação em novembro de 1997, operou com convicções que supunham uma mudança política - democrática e participativa - necessária, segundo seus autores, para reverter uma longa história de perdas, de exclusões e de manutenção de privilégios de minorias. Por isso a sociedade civil se propôs a intervir para mudar essa situação e promoveu amplos debates que tiveram como finalidade construir a tão almejada alternativa educacional.

Uma das virtudes da proposta de Plano Nacional de Educação alternativa foi a de resgatar o método democrático de construção do projeto de LDBEN da Câmara Federal, que foi derrotado e substituído por um outro texto do Poder Executivo de forma autoritária. Ele retoma seus conteúdos, em especial aqueles que davam conta dos direitos educacionais expressos na Constituição Federal de 1988.

Era evidente e explícita a intenção da comunidade educativa de fazer da instituição educacional uma instituição pública inserida socialmente na comunidade, com gestão democrática, práticas participativas com descentralização do poder e socialização das decisões que tivessem como objetivo a consolidação do exercício da cidadania - concebido no plano como a materialização dos direitos fundamentais legalmente constituídos, entre eles o direito à educação. Através da proposta de descentralização do Estado visavam possibilitar, cada vez mais, 
a autonomia didático-pedagógica, administrativa e financeira das instituições educacionais. A unidade do sistema era garantida pela articulação democrática das diferentes esferas de poder (federal, estadual e municipal), tendo em vista a integração de seus planos de educação e também pelo acompanhamento da implementação do plano pela sociedade civil, que se acreditava pressionaria as diferentes esferas de poder para a integração dos mesmos. As diretrizes, princípios, prioridades, metas e estratégias de ação contidas no plano apontavam como necessidade a solução de questões estruturais e também conjunturais, definindo objetivos de longo, médio e curto prazos. Tendo como horizonte a inclusão social e a democracia participativa, a proposta indicava ainda as transformações necessárias para melhorar a qualidade de vida da maioria da população, a conquista da justiça e da igualdade social.

Como é de público conhecimento, o projeto que foi aprovado no Congresso Nacional foi o do "Plano Nacional de Educação - Proposta do Poder Executivo para o Congresso Nacional.” Com isso, o governo lograva impor suas perspectivas ideológicas para o âmbito da educação nacional. Perante essa realidade, os reais problemas educativos brasileiros - tais como a reconhecida falta de qualidade do ensino em todos seus níveis, a falta de democratização do saber escolar, os altos índices de analfabetismo, repetência e de evasão escolar - foram novamente pospostos.

Mesmo atingindo seus objetivos, o governo de Fernando Henrique Cardoso evidenciava sintomas de esgotamento. Isso era semelhante ao ocorrido em outros países de América Latina como Peru e Argentina, que, apesar da adoção de políticas similares, tampouco lograram solucionar seus problemas nacionais sociais (saúde, segurança e educação insuficientes), e estruturais (serviços privatizados de baixa qualidade, o desemprego, e o problema energético de 2001).

A sociedade civil brasileira percebeu que, diante da falta de proposta e de planejamento, eram necessárias mudanças estruturais profundas. As urnas confirmaram essa vontade nas Eleições Municipais (2000) e também nas Eleições Presidenciais (2002). ${ }^{4}$ Porém, o governo eleito de Luís Inácio Lula da Silva deu continuidade às políticas elaboradas pelo governo anterior. Ao que tudo indica, o governo de Lula da Silva abandonou os princípios e a ideologia que caracterizaram a forma de fazer política do Partido dos Trabalhadores (PT) antes de chegar ao poder, ao deixar de lado a opção reivindicada pela maioria do povo brasileiro no período das eleições nacionais: a das mudanças sociais - dentre elas as educacionais, radicais e profundas.

A opção histórica da mudança radical pode ser encontrada num dos 
HERMIDA, J. F. O Plano Nacional de Educação...

escritos de Marx, intitulado "Introdução à crítica da Filosofia do Direito de Hegel”, de 1843. Nele lê-se que:

As armas da crítica não podem, de fato, substituir a crítica das armas; a força material tem de ser deposta por força material, mas a teoria também se converte em força material uma vez que se apossa dos homens. A teoria é capaz de prender os homens desde que demonstre sua verdade face ao homem, desde que se torne radical. Ser radical é atacar o problema em suas raízes. (1991, p. 117)

A partir do exposto, pode-se afirmar que, como os problemas educacionais não estão sendo atacados em suas raízes, o atual governo continua preservando, em matéria educativa, os projetos históricos reafirmados nos governos anteriores.

\section{REFERÊNCIAS}

ANPED. Parecer da ANPED sobre a proposta elaborada pelo MEC para o Plano Nacional de Educação. São Paulo: ANPED, 1997.

BEISIEGEL, C. R. O Plano Nacional de Educação. Cadernos de Pesquisa, São Paulo, n. 106, mar. 1999.

BRASIL. Constituição da República Federativa do Brasil. 21. ed. São Paulo: Saraiva, 1999.

. Emenda Constitucional n. 14 - 12 set. 1996. Diário Oficial da República Federativa do Brasil, 13 set. 1996.

. Lei n. 9.131 - 24 nov. 1995. Diário Oficial da República Federativa do Brasil,

- representada por José Serra (PSDB), 19.700.395 (23,2\%); Antony Garotinho (PSB), 15.175 .729 (17,9\%); Ciro Gomes (PPS), 10.167.597 (12\%); Zé Maria (PSTU), 402.040 (0,5\%); e Rui Costa (PCO), 38.608 (0\%). Votos em branco, 2.873.203 e nulos, 6.975.128. 
HERMIDA, J. F. O Plano Nacional de Educação...

25 nov. 1995.

. Lei n. 9.394 - 24 dez. 1996. Diário Oficial da República Federativa do Brasil, 26 nov. 1996.

. Ministério da Educação e Cultura. Plano Nacional de Educação: proposta do Executivo ao Congresso Nacional. Brasília: MEC/Inep, 1998.

. Ministério da Educação e Cultura. Plano Nacional de Educação: proposta inicial dos procedimentos a serem seguidos. Brasília: MEC, 1997a.

. Proposta para o documento: roteiro e meta para orientar o debate sobre o Plano Nacional de Educação. Brasília: MEC, 1997b.

CONGRESSO NACIONAL DE EDUCAÇÃO. Plano Nacional de Educação: proposta da sociedade brasileira. Belo Horizonte: APUBH, 1997.

CURY, C. R. J. Plano Nacional de Educação: duas formulações. Cadernos de Pesquisa, São Paulo: Fundação Carlos Chagas, n. 104, jul. 1998.

LEHER, R. Um novo senhor da educação? A política educacional do Banco Mundial para a periferia do capitalismo. Outubro, São Paulo: Instituto de Estudos Sociais, n. 3, 1999 .

MARX, K. A questão judaica. 2. ed. São Paulo: Moraes, 1991.

SAVIANI, D. A nova LDB. Campinas: Autores Associados, 1997.

. Da nova LDB ao novo Plano Nacional de Educação: por uma outra política educacional. Campinas: Autores Associados, 1998.

VALENTE, I. Plano Nacional de Educação. Rio de Janeiro: DP\&A, 2001.

Texto recebido em 15 nov. 2004 Texto aprovado em 13 maio 2005 